\title{
Analysis of Water Balance Components and Parameter Uncertainties Based on SWAT Model with CMADS Data and SUFI-2 Algorithm in Huangbaihe River Catchment, China
}

\author{
Huijuan Bo*(**), Xiaohua Dong*(**)†, Zhonghua Li***, Gebrehiwet Reta*(**), Lu li*(**) and Chong Wei*(**) \\ *China Three Gorges University, College of Hydraulic and Environmental Engineering, Yichang, 443002, China \\ **Hubei Provincial Collaborative Innovation Center for Water Security, Wuhan, 430070, China \\ ***Comprehensive Law Enforcement Bureau for Protection of Water Resources in the Huangbaihe River Basin, \\ Yichang, Hubei, 443005, China \\ †Corresponding author: Xiaohua Dong; bohuijuan027@126.com
}

Nat. Env. \& Poll. Tech.

Website: www.neptjournal.com

Received: 05-08-2019

Accepted: 07-11-2019

Key Words:

SWAT model; Streamflow; SUFI-2 algorithm;

Parameter uncertainty analysis; Water balance components

\begin{abstract}
The Huangbaihe River is the primary water source for Yichang city. Large-scale phosphate mining activities in the Huangbaihe River Catchment area could change the proportion of streamflow components; therefore, an accurate simulation of streamflow and its components is vital to enable effective water resource management and protection. In this study, the Soil and Water Assessment Tool (SWAT) model with input data from China Meteorological Assimilation Driving Datasets (CMADS) and the traditional gaging station was applied to simulate hydrological processes in the upper reaches of the Huangbaihe River Catchment area. The constructed model was calibrated and validated using observed streamflow on a monthly scale. Parameter sensitivity and uncertainty analysis were conducted using the Sequential Uncertainty Fitting (SUFI-2) algorithm, and the strengths of calibration and uncertainty analysis were evaluated by applying the $p$-factor (proportion of measurements covered by the 95PPU) and r-factor (mean thickness of 95PPU band separated using the standard deviation of measurements). The results show that the SWAT model with the two kinds of data source proficiently simulated streamflow records compared with only one data from traditional gauging stations in both the calibration and validation periods at the whole outlet. For the calibration (2009-2012) and validation (2013-2016) periods, the statistical indexes are all good at the Xuanmiaoguan gaging station and the whole outlet. Furthermore, spatiotemporal changes in overland runoff and lateral flow were strongly consistent with precipitation, and significant differences in the contribution from hydrological elements to the water balance were observed between high and low-flow years.
\end{abstract}

\section{INTRODUCTION}

Global problems associated with water quantity and quality (such as floods and droughts, water quality deterioration, and eutrophication) are attracting increasing scientific, political, and public attention. The hydrological cycle and processes are complex within a region or watershed, and they are affected by both natural and human-related phenomena, such as heterogeneous soil characteristics, variations in land use and cover, climate change, and other factors (Mou et al. 2015, Dey \& Mishra 2017, Wu et al. 2017). To enable effective water resource management within a region, it is necessary to study the water balance and the various hydrological elements (Dhami et al. 2018, Shawul et al. 2013). Hydrological models are effective tools that have been employed in recent years to provide a visual representation of hydrological processes and accurate flow simulations, particularly when assessing the impacts that land-use change and climate variability have on hydrological cycles and water balance components (Dong et al. 2015).

The SWAT model is a commonly used semi-distributed model (Arnold et al. 1998) that has been applied to predict the hydrological cycle within basins and to quantify nutrient migration, transformation, and large quantities of load within watersheds (Nie et al. 2011, Gan et al. 2015, Abbaspour et al. 2015, Abubakari et al. 2017). However, calibrating the model is challenging, and analysing uncertainties is the focus of much hydrological model research (Uniyal et al. 2015, Song et al. 2015). There are four main sources of uncertainty associated with the model: the model structure, the parameters, input data, and the operational model. In this respect, the uncertainty of the model structure mainly originates from over-simplifying hydrological processes in the natural world (Zhao et al. 2018); model input uncertainty relates to limitations in data representation and observational errors within the studied watershed; uncertainty with respect to the operational model 
originates from human errors; and parameter uncertainty is associated with the large numbers of parameters and equifinality in the model. Of these uncertainties, model input should relate to an area in space and time, and parameter uncertainties can be minimized through an appropriate calibration method. Various techniques have been applied to analyse these uncertainties, including the Markov chain Monte Carlo (MCMC) method (Yang et al. 2008), parameter solution (ParaSol) (Wu \& Chen 2015), SUFI-2 (Abbaspour et al. 2015, Narsimlu et al. 2015) and generalized likelihood uncertainty estimation (GLUE) (Gong et al. 2011).

Currently, numerous studies are focusing on model input and parameter uncertainty issues in SWAT models (Yatheendadas et al. 2008, Zhang et al. 2009, Li et al. 2010, Yang et al. 2018). For regions that have scarce observational data, input data have been developed using satellites that provide data on different spatiotemporal scales (Thiemig et al. 2013, Serrat et al. 2016, Tramblay et al. 2016). Accordingly, CMADS data (from 2008 to 2016) provided by the China Institute of Water Resources and Hydropower Research (IWHR) (Liu et al. 2018) have been applied in certain areas and can produce a better runoff simulation for incorporation into the SWAT model (Meng et al. 2017, Li et al. 2019).

The Huangbaihe River is a first-order tributary of the Yangtze River and the primary water source of Yichang City. However, there have been reductions in water quantity and quality in recent years within the Huangbaihe River Catchment in relation to intense climate variations and human interaction. Hence, it is extremely important to make an accurate prediction of streamflow to enable proficient water resource management. Although CMADS data have been applied in many basins in China where traditional weather stations are scarce, to the best of the author's knowledge, they have not been applied in the Huangbaihe River Basin. For example, the study of Wan et al. 2018 used traditional weather data to simulate streamflow in the Huangbaihe River Basin but the simulation accuracy in the upper reservoir watershed was inadequate.

Therefore, meteorological data from CMADS and traditional weather stations were both employed as SWAT model inputs in this study, enabling the prediction of streamflow in the upper reaches of the Huangbaihe River Catchment. Parameter sensitivity and uncertainty analyses and model calibration and validation were conducted by applying the SUFI-2 algorithm, and water balance components were then investigated based on the simulation outputs. Furthermore, spatiotemporal changes in hydrological components were identified, and the relationships between water balance components and precipitation were finally determined.

\section{MATERIALS AND METHODS}

\section{Site Description}

The studied catchment area is located within the east branch of Huangbaihe River that lies between $110^{\circ} 04^{\prime}$ and $111^{\circ} 30^{\prime}$ E longitude and $30^{\circ} 42^{\prime}$ and $31^{\circ} 29^{\prime} \mathrm{N}$ latitude (Fig. 1).

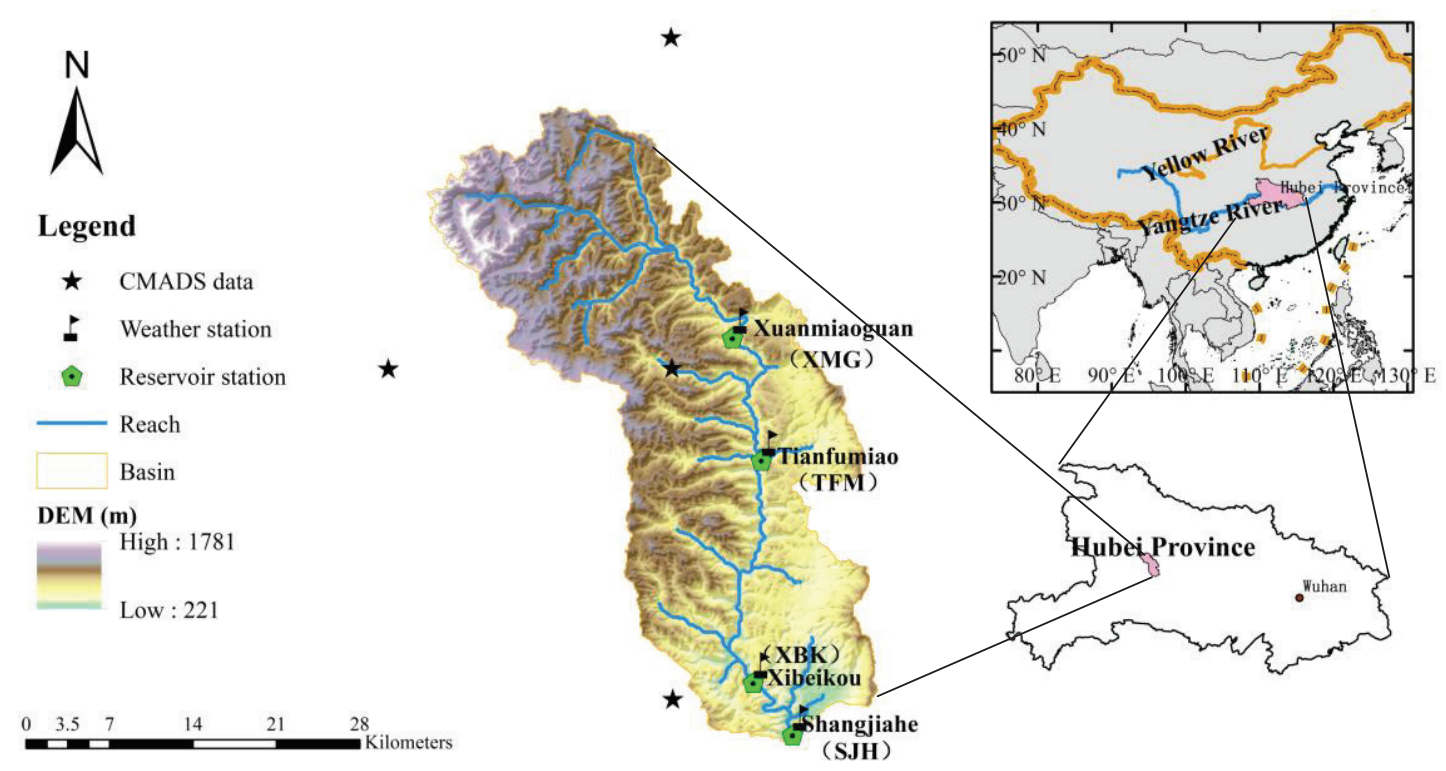

Fig. 1: Digital Elevation Model (DEM), rivers, and locations of discharge observation stations in Huangbaihe River Catchment. 
The elevation ranges from $221 \mathrm{~m}$ above sea level (a.s.l.) at the outlet to $1781 \mathrm{~m}$ a.s.l. at the headstream and the area measures $937.97 \mathrm{~km}^{2}$. The angles of slopes in most areas of the catchment are larger than $25^{\circ}$, and the average slope has an angle of $19.73^{\circ}$. The climate lies within the humid subtropical monsoon region, and mean annual precipitation and temperature are $1101 \mathrm{~mm}$ and $16.9^{\circ} \mathrm{C}$ respectively. The rainy season can extend from May to October, and there is heavy rainfall during summer.

The main land use types are forestry and agriculture, and these occupy percentage land areas of $81.4 \%$ and $15.3 \%$, respectively. Other land cover types are urban (1.9\%) and water $(1.3 \%)$. Bare land is rare and is primarily distributed in mountainous areas, where large-scale phosphate mining activities are conducted. The main soil types are Lithosols and Chromic Cambisols (I-Bc-2c) and Orthic Acrisols (Ao13-3bc), which cover $48.6 \%$ and $42.6 \%$, respectively. Other soil types are Calcic Cambisols (Bk42-2b) and Lithosols and Eutric Cambisols (I-Be-2c).

The following four dams were constructed from upstream to downstream in the study area in 2005, 1978, 1991, and 1971, respectively: Xuanmiaoguan (hereafter referred to as XMG), Tianfumiao (TFM), Xibeikou (XBK), and Shangjiahe $(\mathrm{SJH})$. Over the past 40 years, the study catchment has experienced industrialization and rapid economic growth, which has resulted in serious soil erosion and nutrient loss.

\section{Input Data}

The Shangjiahe (SJH) reservoir dam was chosen as the outlet for the catchment, which is determined by the limitation of data accessibility. To derive the SWAT model, spatial and temporal data of soil characteristics, land use, and topography were acquired, and a DEM map was employed. To calibrate the model, hydrological and meteorological data were applied. The datasets are summarized in Table 1.

Spatial data: A DEM map (Fig. 1) of the study catchment was obtained from the Geospatial Data Cloud website (http://srtm.csi.cgiar.org/). The map has a spatial resolution of 3 arc-seconds (approximately $90 \mathrm{~m}$ ), and it was used to derive the river network, sub-catchments divisions, and slope reclassifications.

The land cover/land use data map was obtained from 2015 LANDSAT data and downloaded from http://www. gscloud.cn/sources/. It was then reclassified using supervised image classification, and five classes of land use data were determined: agricultural field (AGRL), forest (FRST), bare land (BARR), urban (URBN), and water (WATR) (Fig. 2).

The soil types were initialized by applying the FAO-UNESCO Digital Soil Map of the World (DSMW) (http://www. fao.org/geonetwork), where soil information provided by the DSMW has a resolution of $5 \mathrm{~km}$. Four soil classes were identified in the study catchment (Fig. 2), and the corresponding lookup table was subsequently manually generated.

Streamflow data and meteorological elements: Monthly streamflow data and a subset of precipitation datasets were collected from the Huangbaihe Catchment Authority, and a further precipitation dataset subset was obtained from CMADS version 1.1 (http://westdc.westgis.ac.cn/). Other meteorological elements were generated using SWAT's weather generator (WGEN). The data employed to construct WGEN was obtained from the National Centres for Atmospheric Prediction (NCEP). Weather stations w3231134 and w3261138 were included to calculate statistical parameters of the study catchment for WGEN (https://globalweather. tamu.edu/).

\section{Description and Application of SWAT Model}

The SWAT is a watershed-scale, continuous-time, and semi-distributed hydrological model that incorporates meteorological elements, soil characteristics, land cover/use, and management practices to predict streamflow, sediments, nutrient loading, pesticide transport, and so on (Arnold et al. 1998). It enables the simulation of spatial details by dividing the whole watershed into a series of sub-watersheds. Each sub-watershed then comprises hydrologic response units (HRUs) that represent homogenous soil properties, land cover, and slopes. Surface runoff, soil water, nutrient cycles, sediment, and crop yields are calculated within each

Table 1: Input data for model and their sources.

\begin{tabular}{|lll|}
\hline Data type & Spatial Resolution/Time period & Source \\
\hline DEM & $90 \mathrm{~m}$ & Geospatial Data Cloud website (http://srtm.csi.cgiar.org/) \\
Land use & $30 \mathrm{~m}$ & 2015 LANDSAT data (http://www.gscloud.cn/sources/) \\
Soil & $5 \mathrm{~km}$ & FAO-UNESCO Digital Soil Map of the World (DSMW) (http://www.fao.org/geonetwork) \\
Precipitation & $28 \mathrm{~km}$ for CMADS data and 2009- & CMADS version 1.1 (http://westdc.westgis.ac.cn/) and gauging station for Huangbaihe \\
& 2016 for observations & Catchment Authority \\
Streamflow & $2009-2016$ & Gauging station for Huangbaihe Catchment Authority \\
\hline
\end{tabular}




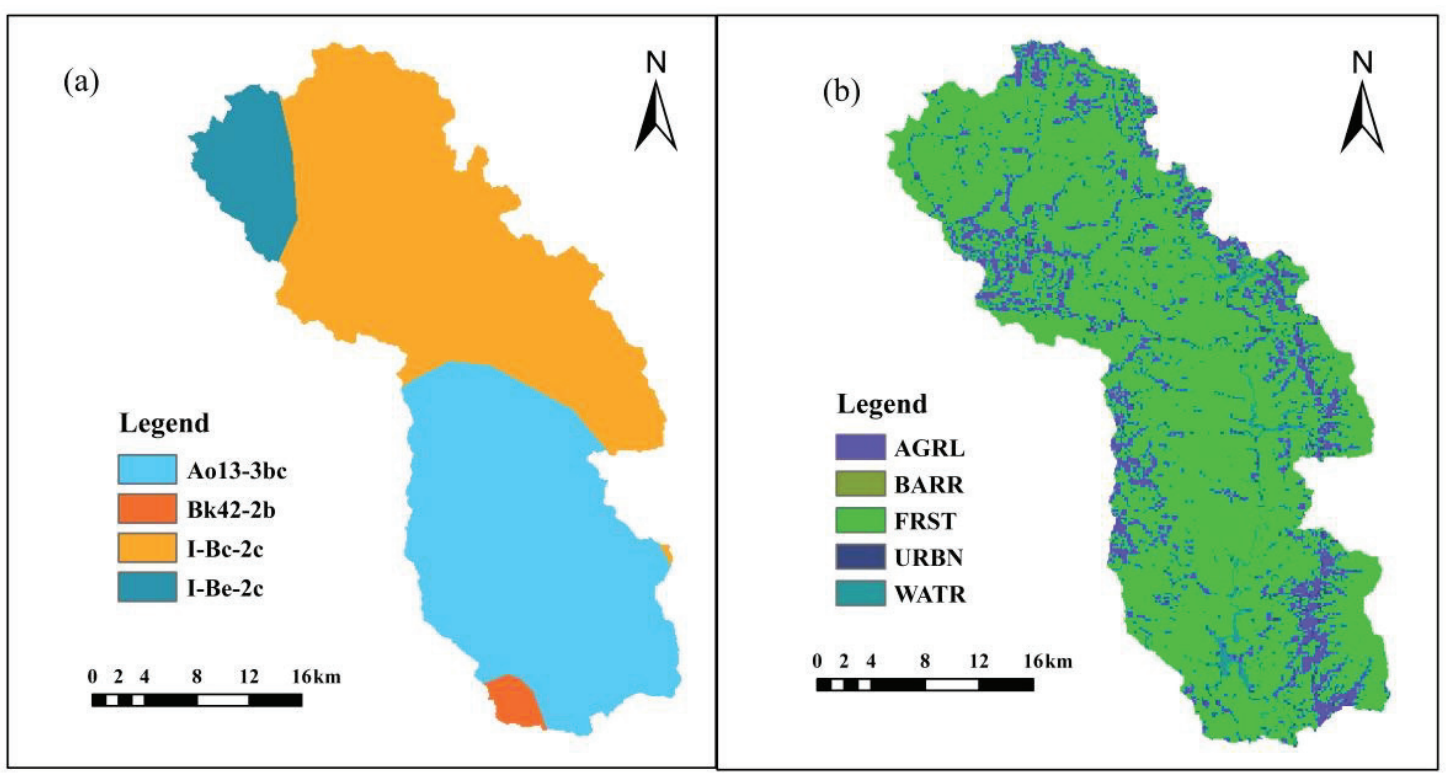

Fig. 2: (a) Soil data; (b) Land-use data

HRU (i.e., the smallest element), and they are subsequently lumped to the sub-catchment using the weighted mean method and finally routed into river systems. Four water storage types are assumed: surface runoff, soil water, and shallow and deep aquifers. The SWAT model assumes that shallow groundwater runs into the river channel as base flow or returns to the soil by evaporation, whereas flow in deep aquifers leaves the watershed system. Details of the SWAT model are provided by Neitsch et al. (2011) and can also be obtained from http://swatmodel.tamu.edu.

In this study, the following calculation methods were employed: the SCS curve number method for overland flow; kinematic storage routing for lateral flow (which creates a shallow aquifer and thus return flow); the Penman-Monteith method for potential evapotranspiration; and the variable storage routing method for channel routing. The Huangbaihe River Catchment was delineated by the interface of SWAT2012 using the 90-m DEM. The boundary of the study catchment was delineated by applying a threshold area of 1400 ha to ensure that the extracted river networks were consistent with the topographic map. Furthermore, a total of 27 sub-catchments were delineated for the SWAT model, and maps of soil and land cover were clipped at the catchment boundary. All layers were projected in the "WGS_1984_UTM_Zone_49N" coordinate system. Soil and land use types were linked using lookup tables, space databases, and attribute databases. Through reclassifying the soil layers and types, land cover/use, and slope classes, the sub-catchment layer was overlaid on the HRU layer. The threshold levels for soil, land use, and slope class percentages were provided for the SWAT model and were used to define the HRUs. In this study, a threshold percentage (10\%) was adopted for all databases, and 202 HRUs were finally established in the SWAT model.

\section{Model Calibration, Validation and Uncertainty Analysis}

Model calibration of the SWAT model is challenging, and two techniques can be employed in calibration: a manual (trial-and-error) method and an auto-calibration method. However, a parameter sensitivity and identifiability analysis should first be conducted before model calibration. Parameter sensitivity is analysed to determine which parameters significantly influence the model simulation results, and parameter sensitivity varies between catchments; therefore, it has been suggested that it is necessary to conduct a sensitivity analysis in every catchment (Cibin et al. 2010).

The SWAT Calibration Uncertainty Procedure (SWATCUP) program (Abbaspour 2015) was adopted in this study. SWAT-CUP is a useful tool that facilitates parameter sensitivity analysis, model calibration and validation procedure by different optimization methods. It can also be used to conduct an uncertainty analysis of the model's operation results. Of these methods, we chose the SUFI-2 algorithm (Yang et al. 2008), because it has been extensively used to analyse parameter sensitivities and all uncertainty sources can be considered (Wu \& Chen 2015), including uncertainties related to input data, model structure, and a large number 
of parameters. Uncertainty is quantified based on $95 \%$ prediction uncertainty (95PPU) band. Two statistics are used to evaluate the strength of the uncertainty analysis, the p-factor (proportion of measurements covered by the 95PPU) and the r-factor (mean thickness of the 95PPU band separated using the standard deviation of measurements). In general, when the value of the p-factor is equal to 1 and the $r$-factor is equal to 0 , the simulation results are considered to have an exact match with the observed data (Abbaspour et al. 2015). It is therefore desirable to achieve a balance between the p- and $r$-factors, as a large $p$-factor can raise the value of the $r$-factor. Details about SUFI-2 and other approaches are given in the work of Abbaspour (2015).

Based on data availability, the model was calibrated for streamflow on a monthly time scale for the period 2009-2012 after a one-year warm-up (2008), which was conducted to enable the parameters to reach an equilibrium state. In general, the length of the warm-up period is determined by the watershed properties and the length of available data. For model validation, four years from 2013 to 2016 were employed. Streamflow data for the whole outlet (sub-catchment 27) of the study catchment area were calculated by applying the water balance method, and streamflow data were thus restored to a natural condition without considering the dams that have been constructed. To check the accuracy of model prediction, streamflow data at an additional upstream station (sub-catchment 9) were also used to calibrate and validate the model. NSE was selected as the objective function, as it can reflect the overall model fit (Nash \& Sutcliffe 1970). The original parameter ranges were determined by referring to previous literature relating to similar or close basins, and also by using recommendations from the SWAT manuals, which are guided through an understanding of the given watershed hydrological cycle (Liu et al. 2016, Stehr et al. 2010). The best parameter sets were employed in each iteration, and new ranges were then suggested based on an evaluation of the model. It is of note that some of the suggested ranges were outside of physically meaningful ranges, and they were thus manually adjusted to ensure that they did not exceed maximum/minimum absolute range values (Me et al. 2015).

\section{Performance Evaluation}

Both graphical and statistical approaches should be applied to assess model performance (Nyeko 2015). Only using the performance metrics can be misleading and produce unrealistic simulations; hence, a visual inspection of the differences between the hydrographs of simulated and observed data was conducted in this study (Daggupati et al. 2015). Graphical methods, such as streamflow hydrographs, can enable a visual and direct comparison of observed and simulated datasets, and enable trends in variations of flow magnitude and timing to be detected. In addition to using the graphical approach, the agreement between simulated and observed data was also evaluated based on statistical indicators, including the Nash-Sutcliffe efficiency coefficient (NSE), RMSE-observations standard deviation ratio (RSR) and percentage bias (PBIAS).

A positive NSE indicates that the measured data have a positive correlation with simulated data; in contrast, a negative NSE reflects a negative correlation,

$$
N S E=1-\frac{\sum_{i=1}^{n}\left(O_{i}-S_{i}\right)^{2}}{\sum_{i=1}^{n}\left(O_{i}-\bar{O}\right)^{2}} .
$$

The RSR, shown in Eq. (2), has the advantages of providing a scaling factor and error criteria statistics, and these statistics can be used with different constituents (Singh et al. 2005),

$$
R S R=\frac{R M S E}{S T D E V}=\frac{\sqrt{\sum_{i=1}^{n}\left(O_{i}-S_{i}\right)^{2}}}{\sqrt{\sum_{i=1}^{n}\left(O_{i}-\bar{O}\right)^{2}}} .
$$

The PBIAS index determines the average trend between simulations and their corresponding observations (Gupta et al. 1999), as shown in Eq. (3),

$$
\text { PBIAS }=\frac{\sum_{i=1}^{n}\left(O_{i}-S_{i}\right)}{\sum_{i=1}^{n} O_{i}} \times 100
$$

Where, $O_{i}$ and $S_{i}$ are measurements and simulations, respectively, and $\bar{O}$ is the average of the observations. A positive (negative) index reflects that the bias is underestimated (overestimated).

The performance of the model was divided into four categories with respect to flow simulation on a monthly time scale following the research of Moriasi et al. (2007).

\section{RESULTS AND DISCUSSION}

\section{Sensitivity Analysis}

A sensitivity analysis of two outlets of the studied catchment was conducted, where 26 parameters relating to streamflow were used to identify sensitive parameters on a monthly scale (including the curve number (CN2) and parameters of soil properties and topography). The relative changes of the distributed parameters, which are different in every HRU or sub-catchment, were assessed using the Latin hypercube method. The $t$-test was applied in the SWAT-CUP program to determine relatively significant parameters with two statistics 
( the $t$-stat and $p$-value). The parameters with larger $t$-stat values and smaller $p$-values were determined as being sensitive parameters. These two statistics, the sensitivity ranking, initial parameter ranges, final parameter uncertainty ranges, and the best simulated estimate of monthly streamflow are summarized in Table 2 . Only sensitivity parameters ranked from 1 to 15 are listed in Table 2.

The results indicate that parameters associated with surface runoff generation (CN2 and CANMX), the evapotranspiration parameter (ESCO), and soil characteristics (including SOL_Z,SOL_BD, and SOL_AWC) are highly sensitive to the objective function (NSE). Therefore, it can be concluded that both overland flow and sub-surface water significantly affect the streamflow simulation results. The final ranges of the 15 significant parameters can be well applied in model calibration and validation with respect to the two outlets on a monthly time scale.

\section{Model Calibration and Validation}

Many studies have demonstrated that the results of the SWAT model are generally better when using a monthly rather than a daily step (Shen et al. 2010, Jang et al. 2018, Uniyal et al. 2015). Therefore, in this study, monthly streamflow data from January 2009 to December 2016 were adopted to calibrate and validate the SWAT model. Model input parameters were selected carefully for the calibration period (with their respective uncertainty ranges), and the selected parameters were then applied to calibrate the model using the SUFI-2 algorithm. In this study, the NSE was the objective function with a threshold value of 0.5 , and parameters were identified using ranges rather than specific values; the calibrated model can also be used to validate the model using the same parameter ranges. Furthermore, calibration in a single site was not sufficient to the large catchment area, due to the parameters are distributed and heterogeneous. Consequently, multi-site calibrations were better than single-site calibration for the distributed hydrological model.

Observations and simulations for the calibration periods 2009-2012 and the validation period 2013-2016 at the XMG gauging station (the outlet of sub-catchment 9) and the whole out are graphically displayed in the top and bottom of Fig. 3 and Fig. 4, respectively. From the figures, the simulated monthly streamflow trends for both periods are close to those of measurements, and peak flow timings are usually well-simulated. Furthermore, the streamflow characteristics of the studied catchment are similar to those of most watersheds with the same climate; for example, streamflow is higher (lower) in the wet (dry) season. However, the peak flow values are underestimated (overestimated) in 2010 and 2014 (2009 and 2011). It is speculated that this relates to an over- (under-) estimation of precipitation.

The results of statistical indicators for observations and simulations on a monthly scale at the two stations in both the calibration and validation periods are compared in Table

Table 2: Sensitivity, best values, and final optimal parameter uncertainty ranges for streamflow simulation on a monthly scale using SUFI-2

\begin{tabular}{|c|c|c|c|c|c|c|}
\hline Parameters & Ranking value & $t$-stat & $p$-value & Initial parameter ranges & Best estimate & Final parameter uncertainty ranges \\
\hline r_CN2.mgt & 1 & 36.25 & 0 & $-0.5 \sim 0.5$ & 0.05 & $-0.01 \sim 0.11$ \\
\hline v_CANMX.hru & 2 & -30.32 & 0 & $0 \sim 100$ & 1.04 & $0.79 \sim 5.29$ \\
\hline r_SOL_Z.sol & 3 & -9.66 & 0 & $-0.5 \sim 0.5$ & -0.03 & $-1.18 \sim 0.11$ \\
\hline r_SOL_BD.sol & 4 & 8.29 & 0 & $-0.5 \sim 0.5$ & 0.61 & $0.36 \sim 0.8$ \\
\hline v_ESCO.hru & 5 & 8.03 & 0 & $0.01 \sim 1$ & 0.22 & $0.13 \sim 0.3$ \\
\hline r_SOL_AWC.sol & 6 & -7.1 & 0 & $-0.5 \sim 0.5$ & -0.68 & $-0.85 \sim-0.56$ \\
\hline v_ALPHA_BF.gw & 7 & 6.36 & 0 & $0.01 \sim 1$ & 0.42 & $0.41 \sim 0.56$ \\
\hline v_RCHRG_DP.gw & 8 & 5.37 & 0 & $0.01 \sim 1$ & 0.35 & $0.27 \sim 0.42$ \\
\hline r_HRU_SLP.hru & 9 & 4.32 & 0 & $-0.5 \sim 0.5$ & -0.15 & $-0.39 \sim-0.05$ \\
\hline v_SLSUBBSN.hru & 10 & -4.28 & 0 & $-0.5 \sim 0.5$ & 0.33 & $0.21 \sim 0.46$ \\
\hline r_SOL_K.sol & 11 & 4.25 & 0 & $-0.5 \sim 0.5$ & 0.16 & $0.03 \sim 0.2$ \\
\hline v_EPCO.hru & 12 & -3.96 & 0 & $0.01 \sim 1$ & 0.65 & $0.59 \sim 0.92$ \\
\hline v_GWQMN.gw & 13 & -3.23 & 0.001 & $0.0 \sim 1000$ & 345.4 & $190.39 \sim 357.24$ \\
\hline v_CH_K2.rte & 14 & -2.55 & 0.01 & $0.0 \sim 100$ & 4.73 & $0.39 \sim 10.19$ \\
\hline v_GW_REVAP.gw & 15 & -1.66 & 0.09 & $0.02 \sim 0.2$ & 0.15 & $0.14 \sim 0.17$ \\
\hline
\end{tabular}

Note: v: initial parameter value is replaced by an active value; $r$ initial value is changed by multiplying (1+ a given value) (Abbaspour et al. 2007). 
3 and Table 4, respectively. For the XMG gaging station, the NSE, RSR, and PBIAS were 0.81, 0.44, and 2.69 for the calibration period, respectively, and $0.87,0.35$ and 0.7 for the validation period, respectively. For the whole outlet, the NSE, RSR, and PBIAS are 0.91, 0.3, and 4.8 for the calibration period, respectively, and $0.94,0.24$, and -1.53 for the validation period, respectively. These results show that the simulations of both periods are quite good (Moriasi et al. 2007). However, in general, simulated stream flows are all underestimated in both the calibration and validation periods (i.e., PBIAS of 2.69 and 0.7, respectively,) for the $\mathrm{XMG}$ gaging station, and simulated streamflow is underestimated (i.e., PBIAS of 4.8) in the calibration period but overestimated in the validation period (PBIAS of -1.53) at the whole outlet. Compared with the results from the study of Wan et al. (2018), the values of statistical indexes are all better. Therefore, using the SWAT model with inputs from a regular gauging station and CMADS data can provide reliable results for the studied catchment. Furthermore, the calibrated SWAT model can be applied in further research,

Table 3: Evaluation indicators of SWAT performance at the XMG gaging station.

\begin{tabular}{|c|c|c|c|c|c|c|}
\hline \multirow{2}{*}{ Statistics } & \multicolumn{2}{|c|}{ Calibration period (2009-2012) } & \multicolumn{2}{|c|}{ Validation period (2013-2016) } & \multicolumn{2}{|c|}{ Wan et al. (2018) } \\
\hline & Measured & Simulated & Measured & Simulated & Measured & Simulated \\
\hline Mean $\left(\mathrm{m}^{3} / \mathrm{s}\right)$ & 4.62 & 4.50 & 4.91 & 4.87 & & \\
\hline $\operatorname{Median}\left(\mathrm{m}^{3} / \mathrm{s}\right)$ & 2.87 & 3.87 & 3.56 & 3.8 & & \\
\hline Standard deviation $\left(\mathrm{m}^{3} / \mathrm{s}\right)$ & 3.43 & 3.13 & 3.72 & 3.46 & & \\
\hline $\operatorname{Minimum}\left(\mathrm{m}^{3} / \mathrm{s}\right)$ & 1.62 & 1.24 & 1.61 & 0.96 & & \\
\hline $\operatorname{Maximum}\left(\mathrm{m}^{3} / \mathrm{s}\right)$ & 14.46 & 16.37 & 18.23 & 14.16 & & \\
\hline NSE & \multicolumn{2}{|c|}{0.81} & \multicolumn{2}{|c|}{0.87} & 0.64 & 0.86 \\
\hline RSR & \multicolumn{2}{|c|}{0.44} & \multicolumn{2}{|c|}{0.35} & 0.59 & 0.37 \\
\hline PBIAS & \multicolumn{2}{|c|}{2.69} & \multicolumn{2}{|c|}{0.70} & -5.5 & 11.9 \\
\hline $\mathrm{p}$-factor & \multicolumn{2}{|c|}{0.81} & \multicolumn{2}{|c|}{0.83} & 0.78 & 0.80 \\
\hline $\mathrm{r}$-factor & \multicolumn{2}{|c|}{0.65} & \multicolumn{2}{|c|}{0.72} & 1.04 & 0.81 \\
\hline
\end{tabular}
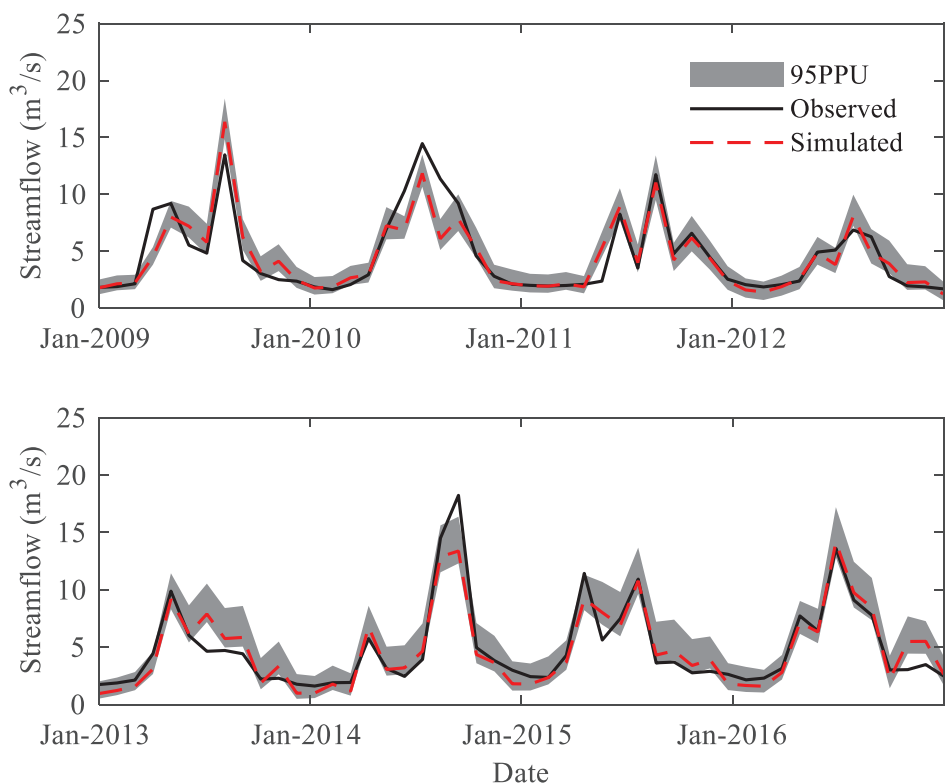

Fig. 3: Observation and simulation at monthly scale for the XMG gaging station in the calibration period of 2009-2012 (top) and the validation period of 2013-2016 (bottom). 

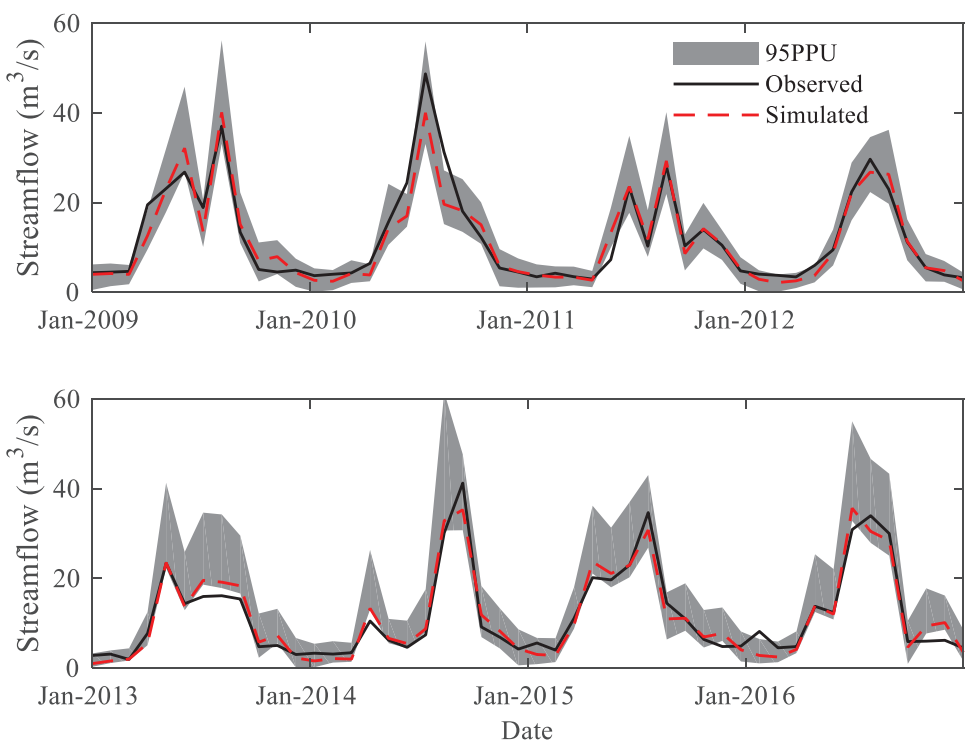

Fig. 4: Observations and simulations on a monthly scale at the whole outlet for calibration period of 2009-2012 (top) and the validation period of 2013-2016 (bottom).

such as that relating to water balance analysis and water quality evaluation.

\section{Uncertainty Analysis}

The $\mathrm{p}$-factor was 0.94 for the calibration period for the whole outlet, which indicates that $94 \%$ of the measured streamflow data were bracketed by the 95PPU band. In addition, the r-factor was 0.84 (Table 4). For the validation period, $85 \%$ of the measured data were bracketed by the 95PPU band (p-factor $=0.85)$, and the $r$-factor was 1.05. Based on previous research (Abbaspour et al. 2015, Schuol et al. 2008), when the $\mathrm{p}$-factor is larger than 0.75 and the simultaneous $\mathrm{r}$-factor is less than 1.5 , the uncertainty of streamflow simulation results is considered to be acceptable. Therefore, it can be deduced that the SUFI-2 algorithm is capable of successfully capturing measured streamflow for both the calibration and validation periods. However, a careful examination of uncertainty analysis results shows that peak flow in 2010 is missing from the 95PPU band, which could be the result of limitations in the SWAT model and associated uncertainties. Therefore, surface runoff generation and groundwater recharge are important in study catchment. The parameters relating to

Table 4: Evaluation indicators of SWAT performance at the whole outlet.

\begin{tabular}{|c|c|c|c|c|}
\hline \multirow{2}{*}{ Statistics } & \multicolumn{2}{|c|}{ Calibration period (2009-2012) } & \multicolumn{2}{|c|}{ Validation period (2013-2016) } \\
\hline & Measured & Simulated & Measured & Simulated \\
\hline Mean $\left(\mathrm{m}^{3} / \mathrm{s}\right)$ & 12.36 & 11.76 & 11.74 & 11.74 \\
\hline $\operatorname{Median}\left(\mathrm{m}^{3} / \mathrm{s}\right)$ & 6.83 & 8.26 & 7.13 & 8.48 \\
\hline Standard deviation $\left(\mathrm{m}^{3} / \mathrm{s}\right)$ & 10.69 & 10.1 & 10.02 & 10.08 \\
\hline Minimum $\left(\mathrm{m}^{3} / \mathrm{s}\right)$ & 2.93 & 2.14 & 1.91 & 0.96 \\
\hline $\operatorname{Maximum}\left(\mathrm{m}^{3} / \mathrm{s}\right)$ & 48.7 & 40.11 & 41.23 & 35.63 \\
\hline NSE & \multicolumn{2}{|c|}{0.91} & \multicolumn{2}{|c|}{0.94} \\
\hline RSR & \multicolumn{2}{|c|}{0.30} & \multicolumn{2}{|c|}{0.24} \\
\hline PBIAS & \multicolumn{2}{|c|}{4.80} & \multicolumn{2}{|c|}{-1.53} \\
\hline p-factor & \multicolumn{2}{|c|}{0.94} & \multicolumn{2}{|c|}{0.85} \\
\hline r-factor & \multicolumn{2}{|c|}{0.84} & \multicolumn{2}{|c|}{1.05} \\
\hline
\end{tabular}


groundwater recharge and overland flow generation are vital hydrological processes. Besides, correlations between parameters were also evaluated, and all values were found to be less than 0.001. Parameter correlations are therefore weak and should be neglected.

\section{Water Balance Components}

Water balance is the foundation and driving force used in watershed analysis when employing the SWAT model. The objective of calibration is to ensure that simulation results are close to the measurements. In this respect, the SWAT model was re-run using the optimal parameters for the entire period (2009-2016) and water-balance components were then identified for the output files. The mean annual contributions of the water balance are listed in Table 5 .

The results show that mean annual precipitation was $1003.8 \mathrm{~mm}$ from 2009 to 2016, which comprises mean annual rainfall $(980.3 \mathrm{~mm})$ and mean annual snowfall $(23.5 \mathrm{~mm})$, and the mean annual actual evapotranspiration comprised $57.03 \%$ of this total $(572.5 \mathrm{~mm})$. Therefore, evapotranspiration was the main form of water loss, which is related to the fact that the predominant land use type is forestry (accounting for $81.41 \%$ of all land use types) (Fig. 2 b). Furthermore, the mean temperature was $16.9^{\circ} \mathrm{C}$, also indicating the larger evapotranspiration. Water yield is streamflow generated at the whole catchment outlet and comprises overland flow, lateral soil flow, and shallow groundwater (baseflow). Water yield was $370.46 \mathrm{~mm}$, which is equal to the total water yield of $396.78 \mathrm{~mm}$ minus that of deep groundwater (26.32 $\mathrm{mm}$ ) because the SWAT model assumes that water entered the deep aquifer flowing out of the catchment (Arnold et al. 1993). Overland flow, lateral subsurface runoff, and baseflow contribute $47.02 \mathrm{~mm}$ (approximately $12.69 \%$ of the total water yield), $201.48 \mathrm{~mm}(54.42 \%)$, and $121.48 \mathrm{~mm}$ (32.79\%), respectively. The proportion of overland flow is high compared to that of other watersheds with a similar percentage of forest cover. This is mainly due to the soil properties within the catchment, where the predominant soil horizon type is $\mathrm{C}(91.2 \%)$ and the remainder is $\mathrm{D}(8.8 \%)$. This indicates a lower infiltration rate with the greater generation of surface runoff (Neitsch et al. 2011). Furthermore, the average slope is $19.73^{\circ}$, which indicates that lateral subsurface runoff is easily generated and perched water flows out. However, there is less groundwater, and this may be related to the amount of water that gushes from the phosphate mining sites. In addition, the proportion of base flow to total runoff is approximately $30 \%$ using the baseflow separation method, which was downloaded from SWAT website (https://swat.tamu.edu/software/). Therefore, the simulation results are reasonable.

The spatial distributions of average annual precipitation, actual evapotranspiration, and each hydrological component (overland runoff, lateral flow, and groundwater) and their contributions to precipitation across the sub-catchments are shown in Fig. 5. The middle of the study catchment receives a greater volume of precipitation. These results indicate that ET rises with a decline in elevation, which is due to the temperature increase at lower altitudes. Besides, the comparison between the spatial distribution of land use (Fig. 2) and ET (Fig. 5) shows that ET is higher in the sub-catchments that have larger river portion (reservoirs). The distribution of the contribution from the overland flow and lateral flow to runoff is consistent with the spatial distribution of precipitation. Furthermore, the distribution of lateral subsurface runoff was also consistent with the variation of elevation. As the

Table 5: Average annual values of hydrological components (in mm/year).

\begin{tabular}{|ll|}
\hline Components & Value (mm/year) \\
\hline Rainfall (PRECIP) & 980.3 \\
Snowfall & 23.5 \\
Surface runoff (SURQ) & 47.02 \\
Lateral soil flow (LATQ) & 201.96 \\
shallow groundwater (GWQ) & 121.48 \\
Deep groundwater & 26.32 \\
Total aquifer recharge & 154.56 \\
Deep aquifer recharge & 26.68 \\
REVAP & 42.19 \\
Total water yield & 396.78 \\
Actual evapotranspiration (AET) & 572.5 \\
Potential evapotranspiration & 1169.5 \\
\hline
\end{tabular}




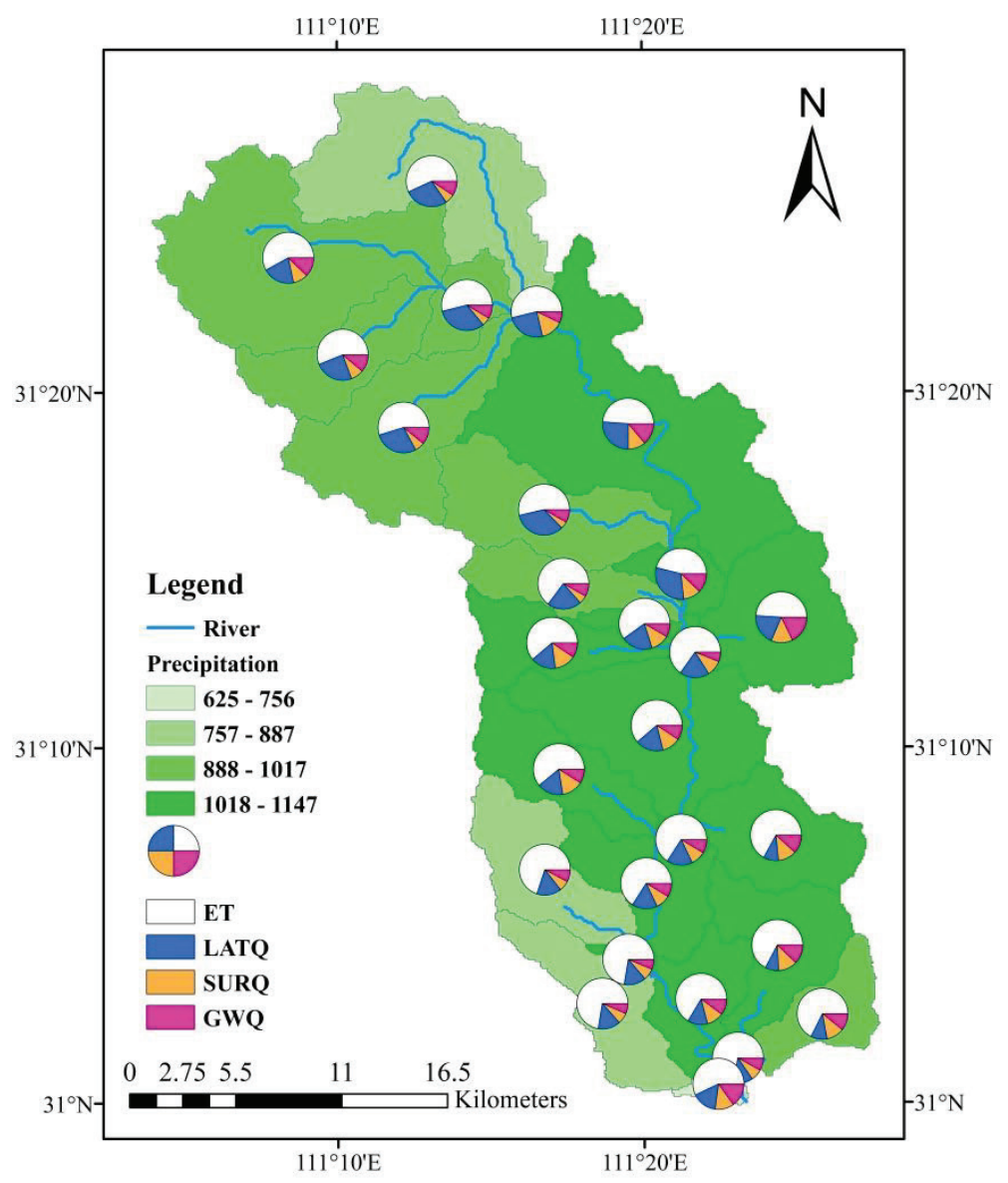

Fig. 5: Spatial distribution of average annual precipitation, actual evapotranspiration, and total water yield.

elevation declined, the contribution of lateral flow decreased. However, the distribution of groundwater contribution was less significant with the distribution of precipitation.

The mean annual contribution values of water balance components from 2009 to 2016 are presented in Fig. 6. It is worthy of note that the annual changes in water yield values (including overland flow, lateral flow, and baseflow) are consistent with annual variations in precipitation. However, the variation in the contribution from overland runoff is contrary to that of precipitation in 2012. Subsequent analysis shows that this relates to the temporal distribution of internal precipitation. In early 2012, the initial soil water content was higher because of excessive rainfall. Therefore, when precipitation continued, a larger amount of surface runoff was generated. However, the annual variation in ET was not significant during the whole period, and the change rate in mean annual ET was approximately $-0.6 \%$.

Monthly values were also computed for the water balance components and are shown in Fig. 7, where it is evident that changes in ET, which is an important source of water loss, were seasonal. ET was reduced in winter and higher in summer. Seasonal changes in overland flow, lateral sub-surface runoff, and groundwater agree with variations in rainfall. The results show that approximately $62.8 \%$ of precipitation occurred during four months from May to August, and the water yield in this period occupied approximately $60.7 \%$ of the annual runoff volume. Furthermore, there was a significant difference in the contribution of hydrological components between the dry and wet seasons. The percentage of overland runoff to precipitation ranged from 0 to $22.26 \%$ on a monthly step, and a clear difference is identified between wet and dry seasons. Groundwater lags behind precipitation, which is a reality in the natural condition.

The relationships between individual water balance components and monthly precipitation were analysed, and the results are presented in Fig. 8. Further, $\mathrm{R}^{2}$ was also calculated to show the significance of correlation relationships. The results show that surface runoff and lateral subsurface flow were significantly influenced by precipitation. The 


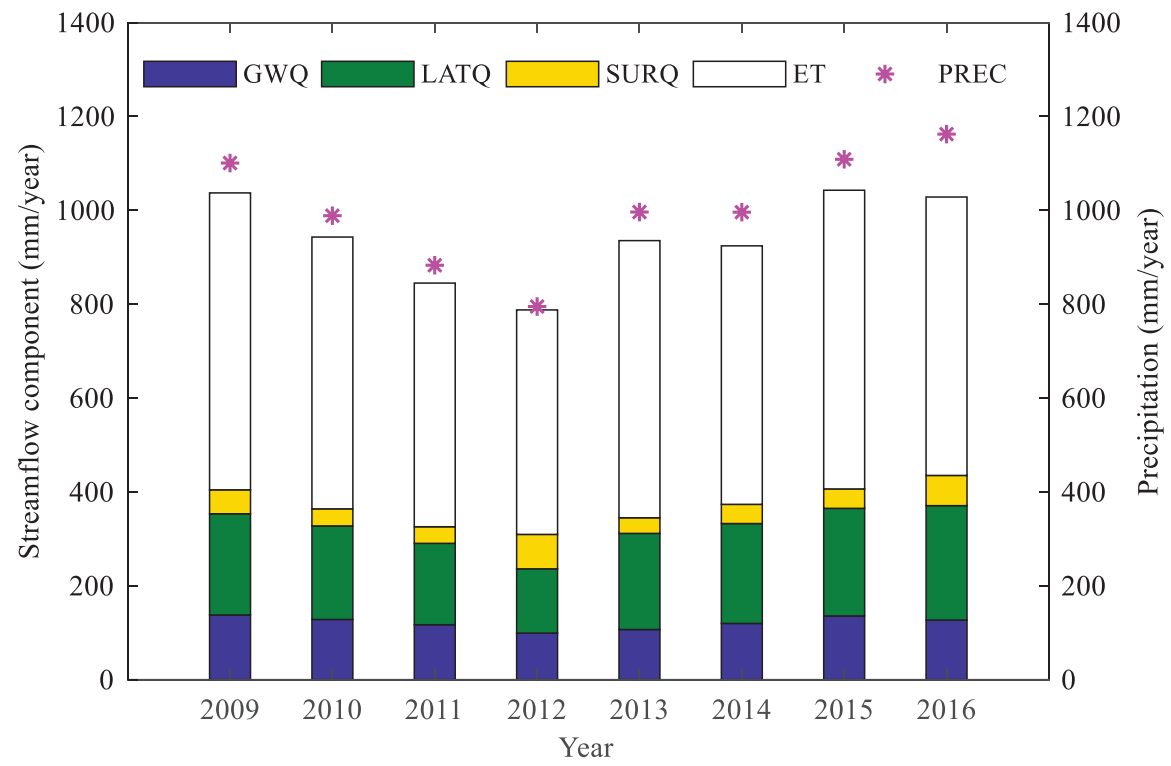

Fig. 6: Mean annual values of water balance components from 2009 to 2016.

curvilinear relationships with $\mathrm{R}^{2}$ were 0.6 for overland flow and precipitation, 0.93 for lateral subsurface runoff and precipitation, and 0.86 for ET and precipitation. Significant indicators were all less than 0.001 , which indicates a significant correlation and implies that intense precipitation can quickly increase overland flow and interflow, thus causing flooding and water pollution. However, there was only a slight increase in groundwater, and this is considered to be because the soil thickness ranges from $2-10 \mathrm{~m}$ in the study catchment (Wang et al. 2016); therefore, groundwater is stable and is less influenced by precipitation. In addition, changes in baseflow are intensively affected by phosphate

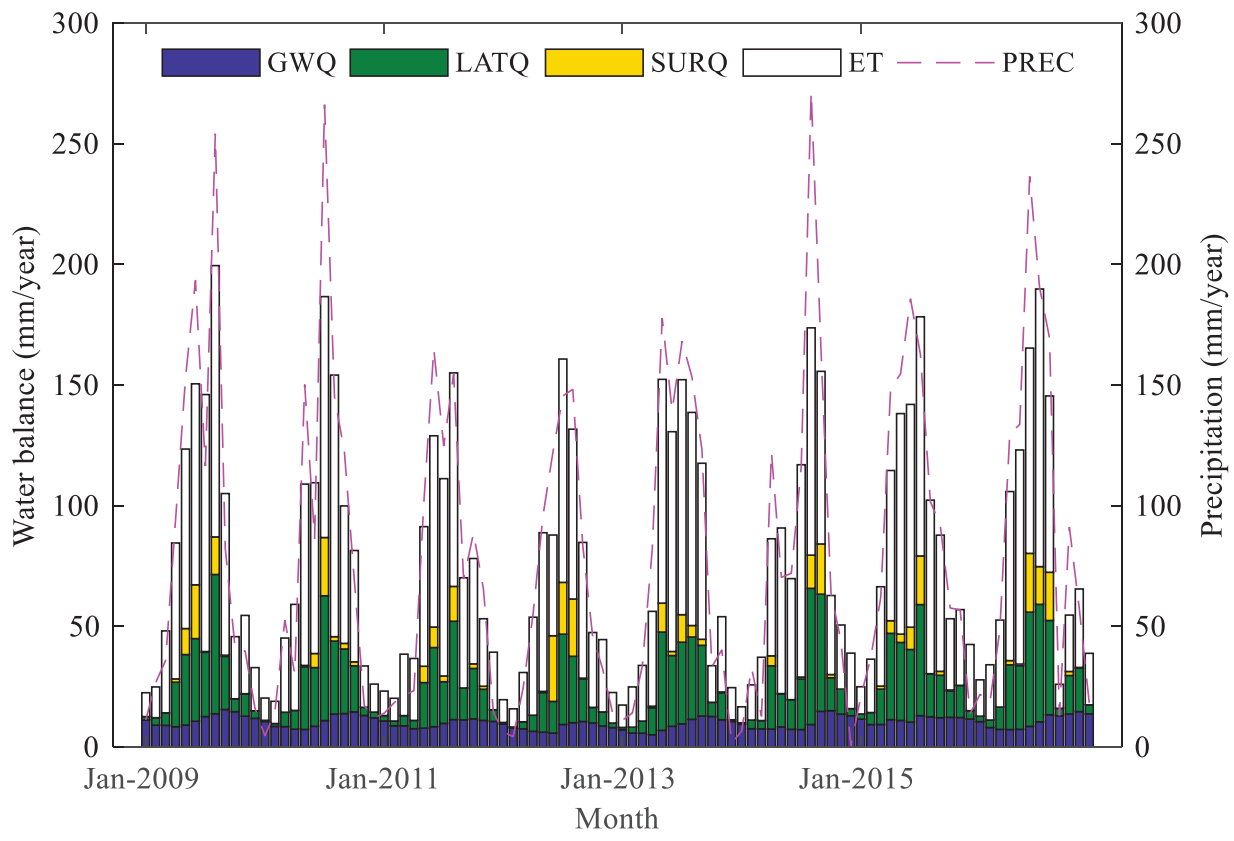

Fig. 7: Monthly values of hydrological components. 
mining activities, and this weakens the correlation between groundwater and precipitation.

\section{CONCLUSIONS}

In this study, two sources of meteorological data, the CMADS data and observations obtained from four gauging stations, were applied to drive the SWAT model in the upper reaches of the Huangbaihe River Catchment. Furthermore, the model was calibrated and validated at multi-sites simultaneously. The results show that the constructed SWAT model successfully simulates monthly streamflow compared with input only from traditional gauging stations. The main results are provided as follows:

(1) A sensitivity analysis of the monthly streamflow simulation shows that CN2, CANMX, and SOL_Z are the most sensitive parameters but the correlation between these parameters is weak. The $\mathrm{p}$ - and $\mathrm{r}$-factor values were acceptable for both the calibration and validation periods, which indicates that the parameters have low uncertainty. Furthermore, the model performed quite well when simulating streamflow on a monthly scale in both the graphical and statistical indexes.
(2) Based on the model output files, mean annual actual evapotranspiration was $572.5 \mathrm{~mm}$, which accounts for approximately $57.03 \%$ of mean annual precipitation $(1003.8 \mathrm{~mm})$. In addition, mean annual streamflow for the whole outlet of the catchment was $370.46 \mathrm{~mm}$. Furthermore, lateral sub-surface flow contributed to approximately $54.53 \%$ of runoff, surface runoff contributed approximately $12.69 \%$, and groundwater baseflow contributed the remaining $32.79 \%$, which is acceptable compared with the result of base-flow separation method (30\%).

(3) The spatial distributions of overland flow and lateral subsurface flow are consistent with the precipitation distribution. The highest ET is distributed in areas where the river occupies a larger area, and where there is more agricultural land cover. ET was stable during the entire period (2009-2016). Based on regression results, apart from groundwater, the surface runoff, lateral flow and ET were significantly related to precipitation.

It is considered that the water balance component results obtained here can be used in water environment protection and sustainable utilization of the Huangbaihe River Catchment.
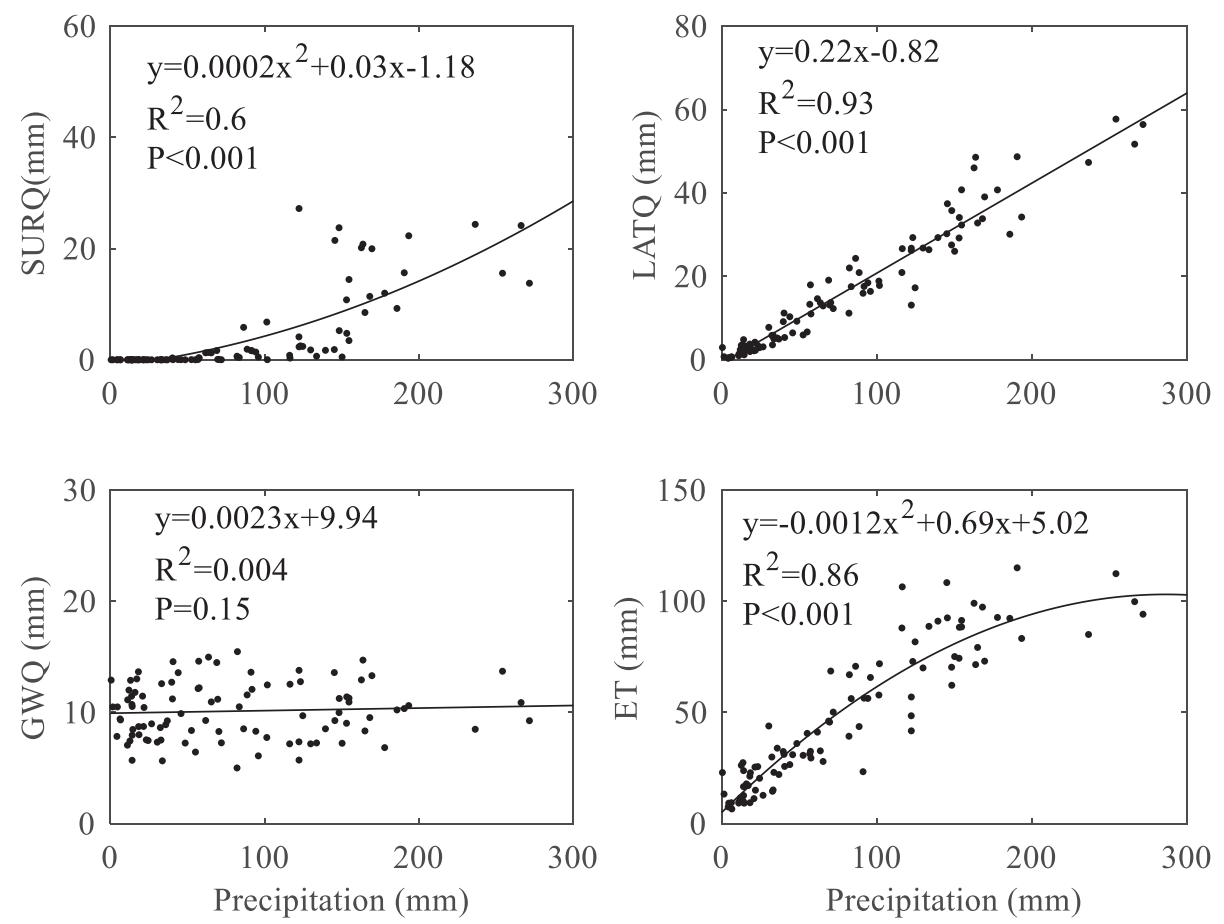

Fig. 8: Relationship between water balance components and precipitation on a monthly time scale (a) overland flow (SURQ) and precipitation; (b) lateral soil flow (LATQ) and precipitation; (c) groundwater (GWQ) and precipitation; (d) evapotranspiration (ET) and precipitation. 


\section{ACKNOWLEDGEMENTS}

We thank the Protection of Water Resources in the Huangbaihe River Basin for providing the runoff and precipitation data. And this paper was supported by the Natural Science Foundation of China (40701024, 41101511, 51409152), the Non-profit Industry Financial Program of Ministry of Water Resources of China (No. 201301066), the PhD Thesis Foundation of China Three Gorges University (2018BSPY003), and the Hubei Provincial Collaborative Innovation Center for Water Security.

\section{REFERENCES}

Abbaspour, K. C. 2015. SWAT-CUP: SWAT Calibration and Uncertainty Programs - A User Manual Eawag, Dübendorf.

Abbaspour, K. C., Rouholahenjad, E., Vaghefi, S., Srinivasan, R., Yang, H. and Klve, B. 2015. A continental-scale hydrology and water quality model for Europe: Calibration and uncertainty of a high-resolution large-scale SWAT model. Journal of Hydrology, 524: 733-752.

Abbaspour, K. C., Yang, J., Maxomov, I., Siber, R., Bonger, K., Mieleitner, J., Zobrist, J. and Srinivasan, R. 2007. Modelling hydrology and water quality in the pre-alpine/alpine Thur watershed using SWAT. Journal of Hydrology, 333: 413-430.

Abubakari, S., Dong, X. H., Su, B., Hu, X. N., Liu, J., Li, Y. H., Peng, T., Ma, H. B., Wang, K. and Xu, S. J. 2017. Modelling the Spatial Variation of Hydrology in Volta River Basin of West Africa under Climate Change. Nature Environment and Pollution Technology, 16(4): 1095-1105.

Arnold, J. G., Allen, P. M. and Bernhardt, G. 1993. A comprehensive surface-groundwater flow model. Journal of Hydrology, 142: 47-69.

Arnold, J. G., Srinivasan, R., Muttiah, R. S. and Williams, J. R. 1998. Large area hydrologic modeling and assessment-Part I: Model development. Journal of the American Water Resources Association, 34: 73-89.

Cibin, R., Sudheer, K. P. and Chaubey, I. 2010. Sensitivity and identifiability of stream flow generation parameters of the SWAT model. Hydrological Processes, 24: 1133-1148.

Daggupati, P., Yen, H., White, M. J., Srinicasan, R., Arnold, J. G., Keitzer, C. S. and Sowa, S. P. 2015. Impact of model development, calibration and validation decisions on hydrological simulations in West Lake Erie Basin. Hydrological Processes, 29: 5307-5320.

Dey, P. and Mishra, A. 2017. Separating the impacts of climate change and human activities on streamflow: A review of methodologies and critical assumptions. Journal of Hydrology, 548.

Dhami, B., Himanshu, S. K., Pandey, A. and Gautam, A. K. 2018. Evaluation of the SWAT model for water balance study of a mountainous snowfed river basin of Nepal. Environmental Earth Sciences, 77: 20.

Dong, W., Cui, B., Liu, Z. and Zhang, K. 2015. Relative effects of human activities and climate change on the river runoff in an arid basin in northwest China. Hydrological Processes, 28: 4854-4864.

Gan, R., Luo, Y., Zuo, Q. and Sun, L. 2015. Effects of projected climate change on the glacier and runoff generation in the Naryn River Basin, Central Asia. Journal of Hydrology, 523: 240-251.

Gong, Y., Shen, Z., Hong, Q., Liu, R. and Liao, Q. 2011. Parameter uncertainty analysis in watershed total phosphorus modeling using the GLUE methodology. Agriculture, Ecosystems and Environment, 142: 246-255.

Gupta, H. V., Sorooshian, S. and Yapo, P. O. 1999. Status of automatic calibration for hydrologic models: Comparison with multilevel expert calibration. Journal of Hydrologic Engineering, 4: 135-143.

Jang, W. S., Engel, B. and Ryu, J. 2018. Efficient flow calibration method for accurate estimation of baseflow using a watershed scale hydrological model (SWAT). Ecological Engineering, 125: 50-67.
Li, Y., Wang, Y., Zheng, J. and Yang, M. 2019. Investigating Spatial and Temporal Variation of Hydrological Processes in Western China Driven by CMADS. Water, 11: 435.

Li, Z., Shao, Q., Xu, Z. and Cai, X. 2010. Analysis of parameter uncertainty in semi-distributed hydrological models using bootstrap method: A case study of SWAT model applied to Yingluoxia watershed in northwest China. Journal of Hydrology, 385: 76-83.

Liu, J., Shang, D., Liu, S. and Ding, Y. 2018. Evaluation and hydrological simulation of CMADS and CFSR reanalysis datasets in the Qinghai-Tibet plateau. Water, 10: 513 .

Liu, R., Xu, F., Zhang, P., Yu, W. and Men, C. 2016. Identifying non-point source critical source areas based on multi-factors at a basin scale with SWAT. Journal of Hydrology, 533: 379-388.

Me, W., Abell, J. M. and Hamilton, D. P. 2015. Effects of hydrologic conditions on SWAT model performance and parameter sensitivity for a small, mixed land use catchment in New Zealand. Hydrology and Earth System Sciences, 19: 4127-4147.

Meng, X., Hao, W., Meng, X. and Hao, W. 2017. Significance of the China meteorological assimilation driving datasets for the SWAT model (CMADS) of East Asia. Water, 9: 765.

Moriasi, D. N., Arnold, J. G., Liew, M. W. V., Bingner, R. L., Harmel, R. D. and Veith, T. L. 2007. Model evaluation guidelines for systematic quantification of accuracy in watershed simulations. Transactions of the Asabe, 50: 885-900.

Mou, L. T., Ibrahim, A. L., Yusop, Z., Zheng, D. and Ling, L. 2015. Impacts of land-use and climate variability on hydrological components in the Johor River basin, Malaysia. International Association of Scientific Hydrology Bulletin, 60: 17.

Narsimlu, B., Gosain, A. K., Chahar, B. R., Singh, S. K. and Srivastava, P. K. 2015. SWAT Model Calibration and uncertainty analysis for streamflow prediction in the Kunwari River Basin, India, using sequential uncertainty fitting. Environmental Processes, 2: 79-95.

Nash, J. E. and Sutcliffe, J. V. 1970. River flow forecasting through conceptual models part I - A discussion of principles. Journal of Hydrology, 10: 282-290.

Neitsch, S. L., Arnold, J. G., Kiniry, J. R. and Williams, J. R. 2011. Soil and water assessment tool theoretical documentation version 2009. Texas Water Resources Institute Technical Report 406.

Nie, W., Yuan, Y., Kepner, W., Nash, M. S., Jackson, M. and Erickson, C. 2011. Assessing impacts of Landuse and Landcover changes on hydrology for the upper San Pedro watershed. Journal of Hydrology, 407: 105-114.

Nyeko, M. 2015. Hydrologic Modelling of Data Scarce Basin with SWAT Model: Capabilities and Limitations. Water Resources Management, 29: 81-94.

Schuol, J., Abbaspour, K. C., Srinivasan, R. and Yang, H. 2008. Estimation of freshwater availability in the West African sub-continent using the SWAT hydrologic model. Journal of Hydrology, 352: 30-49.

Serrat, A., Merino, M., Valdes, J. and Durcik, M. 2016. Evaluation of the performance of three satellite precipitation products over Africa. Remote Sensing, 8: 836.

Shawul, A. A., Alamirew, T. and Dinka, M. O. 2013. Calibration and validation of SWAT model and estimation of water balance components of Shaya mountainous watershed, Southeastern Ethiopia. Hydrol. Earth Syst. Sci. Discuss., 2013: 13955-13978.

Shen, Z. Y., Hong, Q., Yu, H. and Niu, J. F. 2010. Parameter uncertainty analysis of non-point source pollution from different land use types. Science of the Total Environment, 408: 1971-1978.

Singh, J., Knapp, H. V., Arnold, J. G. and Demissie, M. 2005. Hydrological modeling of the Iroquois River Watershed using HSPF and SWAT. Journal of the American Water Resources Association, 41: 343-360.

Song, X. M., Zhang, J. Y., Zhan, C. S., Xuan, Y. Q., Ye, M. and Xu, C. G. 2015. Global sensitivity analysis in hydrological modeling: Review of 
concepts, methods, theoretical framework, and applications. Journal of Hydrology, 523: 739-757.

Stehr, A., Aguayo, M., Link, O., Parra, O., Romero, F. and Alcayaga, H. 2010. Modelling the hydrologic response of a mesoscale Andean watershed to changes in land use patterns for environmental planning. Hydrology and Earth System Sciences Discussions, 14: 1963-1977.

Thiemig, V., Rojas, R., Zambrano, B. M. and Roo, A. D. 2013. Hydrological evaluation of satellite-based rainfall estimates over the Volta and Baro-Akobo Basin. Journal of Hydrology, 499: 324-338.

Tramblay, Y., Thiemig, V., Dezetter, A. and Hanigh, L. 2016. Evaluation of satellite-based rainfall products for hydrological modelling in Morocco. International Association of Scientific Hydrology Bulletin, 61: 2509-2519.

Uniyal, B., Jha, M. K. and Verma, A. K. 2015. Parameter identification and uncertainty analysis for simulating streamflow in a river basin of eastern India. Hydrological Processes, 29: 3744-3766.

Wan, H., Dong, X., Peng, T., Liu, J., Yu, D., Bo, H. and Chen, L. 2018. Application of the SWAT model into the runoff simulation based on SUFI-2 algorithm in the east branch of Huangbai river basin. China Rural Water and Hydropower, 12: 94-100.

Wang, K., Lin, Z. and Zhang, R. 2016. Impact of phosphate mining and separation of mined materials on the hydrology and water environment of the Huangbai River basin, China. Science of the Total Environment, 543: 347
Wu, H. and Chen, B. 2015. Evaluating uncertainty estimates in distributed hydrological modeling for the Wenjing River watershed in China by GLUE, SUFI-2, and Para Sol methods. Ecological Engineering, 76: 110-121.

Wu, L., Wang, S., Bai, X., Luo, W., Tian, Y., Zeng, C., Luo, G. and He, S. 2017. Quantitative assessment of the impacts of climate change and human activities on runoff change in a typical karst watershed, SW China. Science of the Total Environment, 601-602: 1449.

Yang, C., Jing, Z., Yang, M., Lei, X. and Qu, J. 2018. Application of SWAT Model with CMADS data to estimate hydrological elements and parameter uncertainty based on SUFI-2 algorithm in the Lijiang river basin, China. Water, 10: 742.

Yang, J., Reichert, P., Abbaspour, K. C., Xia, J. and Yang, H. 2008. Comparing uncertainty analysis techniques for a SWAT application to the Chaohe Basin in China. Journal of Hydrology, 358: 1-23.

Yatheendadas, S., Wagener, T., Gupta, H., Unkrich, C., Goodrich, D., Schaffner, M. and Anne, S. 2008. Understanding uncertainty in distributed flash flood forecasting for semiarid regions. Water Resource Research, 44: W05S19.

Zhang, X., Srinivasan, R. and Bosch, D. 2009. Calibration and uncertainty analysis of the SWAT model using genetic algorithms and Bayesian model averaging. Journal of Hydrology, 374: 307-317.

Zhao, F., Wu, Y., Qiu, L., Sun, Y., Sun, L., Li, Q., Niu, J. and Wang, G. 2018. Parameter uncertainty analysis of the SWAT model in a mountain-loess transitional watershed on the Chinese Loess Plateau. Water, 10. 